\title{
A ética na escola de Schopenhauer: o caso de Paul Rée
}

\author{
Domenico M. Fazio \\ Università del Salento - Lecce (Itália)
}

\begin{abstract}
RESUMO
Paul Rée (1849-1901) é conhecido sobretudo como amigo de Nietzsche. Mas Rée não é só o amigo que compartilhou com Nietzsche a infeliz paixão por Lou Salomé. Nem seus escritos filosóficos tem sentido só em relação com Nietzsche. Ele foi um filósofo moral autônomo e original e, coerentemente com suas ideias filosóficas, inspiradas no pensamento ético de Schopenhauer, médico e filantropo. Como tal, ele pode ser considerado como expoente daquela que a nova tendência da historiografia schopenhaueriana considera a escola de Schopenhauer em sentido lato.
\end{abstract}

\section{ABSTRACT}

Paul Rée (1849-1901) is known especially as Nietzsche's friend. But Rée is not only the friend who shared with Nietzsche the unhappy passion for Lou Salomé. Nor his philosophical writings have a meaning only in relation to Nietzsche. He was an autonomous and original moral philosopher and, in coherence with his philosophical ideas, inspired to Schopenhauer's moral thinking, physician and philanthropist. As such he can be considered as a member of what the new tendency of the Schopenhauerian historiography calls the school of Schopenhauer in a broad sense.

1. Uma consolidada tradição historiográfica apresenta Schopenhauer como um filósofo isolado no panorama cultural de seu tempo e como um homem solitário, que não tinha alguma escola. Mas o próprio Schopenhauer falava da sua "escola" e distinguia nessa os "apóstolos" - seus discípulos que não escreviam sobre ele - e os "evangelistas" - seus discípulos que escreviam sobre ele ${ }^{1}$. Trata-se dos discípulos diretos de Schopenhauer, que mantiveram uma relação pessoal com ele. É esta que, seguindo a História da filosofia moderna de Kuno Fischer, podemos chamar "a escola dos apóstolos e dos evangelistas", ou podemos chamar também a escola de Schopenhauer em sentido estrito, para distingui-la da escola de Schopenhauer em sentido lato.

A existência de uma escola de Schopenhauer em sentido lato passou a ser, no século XIX, uma ideia largamente aceita na historiografia filosófica, depois que Eduard von Hartmann, em 1883, publicou um artigo com o título A escola de

\footnotetext{
${ }^{1}$ Cf. A. Schopenhauer, Gespräche, hrsg. von A. Hübscher, Stuttgart - Bad Cannstatt 1971, p. 210, a conversa com R. von Hornstein.

${ }^{2}$ Cf. K. Fischer, Schopenhauers Leben, Werke und Lehre, in Geschichte der neuern Philosophie, 9 Bde., Heidelberg 1934, vol. IX, pp. 103-113.
} 
Schopenhauer, em que escreveu que "é possível falar de uma escola de Schopenhauer no sentido mais lato do termo se englobarmos todas as tentativas, a partir dele, de uma transformação de sua filosofia"3. São schopenhauerianos em sentido lato todos os pensadores que se dizem schopenhauerianos ou que foram considerados schopenhauerianos.

As pesquisas do "Centro interdipartimentale di ricerca su Arthur Schopenhauer e la sua scuola" da Universidade do Salento na Itália tem o objetivo de determinar os limites desta escola de Schopenhauer em sentido lato e de estudar o pensamento de cada personalidade que dela faz parte. Um primeiro resultado é uma classificação no interior da escola em sentido lato que - continuando a metáfora schopenhaueriana inspirada na história da Igreja - distingue "os metafísicos" - pensadores como Eduard von Hartmann, Julius Bahnsen e Philipp Mainländer, que desenvolvem a metafísica da vontade em forma original - "os heréticos" - filósofos como Friedrich Nietzsche, Georg Simmel e Max Horkheimer, que desenvolvem de forma autônoma especialmente a doutrina ética do mestre - e "os pais fundadores" - intelectuais como Paul Deussen, fundador da Sociedade Schopenhauer, a qual festeja este ano o seu centenário, Hans Zint e Arthur Hübscher, que foram ativos especialmente no estudo e na divulgação do pensamento de Schopenhauer ${ }^{4}$. Um segundo resultado é a inclusão, na escola de Schopenhauer, de alguns pensadores que, apesar de não serem considerados como sequazes de Schopenhauer pela historiografia filosófica tradicional, entram plenamente na definição da escola de Schopenhauer em sentido lato, em quanto se dizem schopenhauerianos e foram considerados schopenhauerianos. É o caso de Paul Rée.

2. Paul Rée (1849-1901) é conhecido sobretudo como amigo de Nietzsche. Ele é o terceiro personagem de uma célebre fotografia que todo mundo conhece. Tirada em 1882 em Lutzern, representa a chamada "trindade": uma senhora está sobre uma charrete, que é puxada por dois homens. A senhora sobre a charrete é a estudante Lou Salomé, que tem em sua mão um chicote - o mesmo chicote que,

\footnotetext{
${ }^{3}$ E. von Hartmann, Die Schopenhauer'sche Schule, in Philosophische Fragen der Gegenwart, Berlin 1885 , p. 39.

${ }^{4}$ Cf. D. M. Fazio, M. Koßler, L. Lütkehaus, Arthur Schopenhauer e la sua scuola, Lecce 2007; Schopenhauer und die Schopenhauer-Schule, hrsg. von F. Ciracì, D. M. Fazio, M. Koßler, Würzburg 2009; La scuola di Schopenhauer. Testi e contesti. a cura del Centro interdipartimentale di ricerca su Arthur Schopenhauer e la sua scuola dell'Università del Salento, Lecce 2009.
} 
trocando as partes, se tornou célebre no Zarathustra: "Vais às mulheres? Pois leve o chicote" ${ }^{\prime 5}$ Os dois homens, que estão puxando a charrete são Friedrich Nietzsche e Paul Rée.

Todavia, como se tem evidenciado a partir das pioneiras pesquisas de Hubert Treiber $^{6}$, e das de quem escreve ${ }^{7}$ aqui, Rée não é só o amigo que compartilhou com Nietzsche a infeliz paixão por Lou Salomé. Nem seus escritos filosóficos tem sentido só em relação com Nietzsche. Ele foi um filósofo moral autônomo e original e, coerentemente com suas ideias filosóficas, médico e filantropo e, como tal, pode ser considerado como expoente daquela que a nova tendência da historiografia schopenhaueriana considera a escola de Schopenhauer em sentido lato ${ }^{8}$.

Como estudante de filosofia na universidade helvética de Zurique e schopenhaueriano ele se apresentou a Paul Deussen no verão de $1872^{9}$ e, como schopenhaueriano, no ano seguinte foi acolhido em Basileia no grupo de Nietzsche, o qual escreveu numa carta: "Chegou aqui, para ficar todo o verão, um amigo de Romundt, uma pessoa muito reflexiva e dotada: um schopenhaueriano de nome Rée" ${ }^{10}$.

Como schopenhaueriano ele ficou conhecido entre seus contemporâneos e entres os schopenhauerianos foi incluído pelo anônimo crítico da revista inglesa

\footnotetext{
${ }^{5}$ F. Nietzsche. Also sprach Zarathustra, in Sämtliche Werke, Kritische Studienausgabe hrsg. von G. Colli u. M. Montinari, 15 Bde., Berlin - New York 1999, Bd. 4, p. 86: "Von alten und jungen Weiblein".

6 Cf. H. Treiber, Paul Rée - ein Freund Nietzsches, in "Bündner Jahrbuch" 1987, pp. 35-59; Gruppenbilder mit einer Dame, in "Forum", 1988, pp. 40-54; Zur Genealogie einer "Science positive de la Morale en Allemagne". Die Geburt der "r(é)ealistischen Moralwissenschaft" aus der Idee einer monistischen Naturkonzeption, in "Nietzsche-Studien", 22, 1993, pp. 165-221; Paul Rée - nicht nur ein Freund Nietzsches, in Nietzsche und die Schweiz, hrsg. von D. M. Hoffmann, Zürich 1994, pp. 69-83; Nachträge zu Paul Rée, in "Nietzsche-Studien", 27, 1998, pp. 515-516; Ausgewählte Aspekte zu Paul Rées Straftheorie, in Nietzsche und das Recht, hrsg. von K. Seelmann, Stuttgart 2001, pp. 151-167; Eine quellenmäßige Erschließung von Paul Rées Schrift "Die Illusion der Willensfreiheit" (1885): Auf der Suche nach Schopenhauer, in Schopenhauer und die Schopenhauer-Schule, cit., pp. 271-288. As pesquisas de H. Treiber culminam com a edição das obras de Rée: P. Rée, Gesammelte Werke 1875-1885, hrsg. von H. Treiber, Berlin-New York 2004.

7 Cf. D. M. Fazio, Paul Rée. Un profilo filosofico, Bari 2003, também em Alemão, Paul Rée. Philosoph, Arzt, Philanthrop, München 2005; D. M. Fazio, Intoduzione, a P. Rée, Osservazioni psicologiche, a cura di D. M. Fazio, Lecce 2010, pp. 9- 96.

${ }^{8}$ Cf. D. M. Fazio, L'aureola della storia universale. Gli scritti di Paul Rée nelle interpretazioni e nelle testimonianze dei contemporanei, in B. Bonghi, F. Minazzi, Sulla filosofia italiana del Novecento, Milano 2008, pp. 227-252; Ein Schopenhauerianer namens Rée, in Schopenhauer und die Schopenhauer-Schule, cit., pp. 289-300.

${ }^{9}$ Cf. P. Deussen, Mein Leben, hrsg. von E. Rosenthal-Deussen, Leipzig 1922, p. 140.

${ }^{10}$ F. Nietzsche, Sämtliche Briefe, Kritische Studienausgabe, hrsg. von G. Colli u M. Montinari, 8 Bde., München 1986, Bd. 4, an Erwin Rohde in Kiel, Basel 5. Mai 1873, p. 150.
} 
"Mind", graças ao seu livro A origem dos sentimentos morais" ${ }^{11}$; foi considerado um sequaz de Schopenhauer por Ferdinand Laban em seu estudo de 1880 sobre a literatura schopenhaueriana ${ }^{12}$ e por Olga Plümacher em sua história do pessimismo $^{13}$. Enfim, Heinrich Romundt, na sua crítica à sua obra póstuma, Filosofia, escreveu que Paul Rée “estava à vontade no pessimismo de Schopenhauer"14.

3. E efetivamente Paul Rée estreou em âmbito filosófico como schopenhaueriano em 1875, editando de maneira anônima - mas com o apoio do maior dos schopenhauerianos do tempo, ou seja, Eduard von Hartmann - um pequeno livro de máximas de filosofia moral com o título Observações psicológicas $^{15}$.

As Observações psicológicas são uma obra de clara inspiração schopenhaueriana já a partir do título. Psychologische Bemerkungen (ou seja Observações psicológicas) é efetivamente o título de uma parte do segundo livro dos Parerga e paralipomena de Schopenhauer ${ }^{16}$ e de um trecho da mesma obra vem a citação de Gobineau que está no frontispício do livro de Rée: “O homem é o animal malvado por excelência"17. Em fim: no capítulo dos Parerga intitulado "A filosofia e seu método" não só é delineado o projeto de pesquisa que Rée efetivamente seguiu na sua obra, mas são também indicados os autores e os livros com os quais ele se confrontou no seu caminho, usando-os como modelos ou como alvos polêmicos.

Nesse trecho Schopenhauer, seguindo Kant, critica a possibilidade da fundação de uma psicologia racional e defende, ao contrário, a utilidade e a oportunidade das pesquisas de psicologia empírica, ou seja, "do conhecimento que provém da observação das manifestações e das peculiaridades morais e intelectuais

\footnotetext{
${ }^{11}$ Cf. Recensão de P. Rée, Der Ursprung der moralischen Empfindungen, in "Mind" 1977, p. 581.

${ }^{12}$ Cf. F. Laban, Die Schopenhauer-Literatur, Leipzig 1880, p. 20.

${ }^{13}$ Cf. O. Plümacher, Der Pessimismus in Vergangenheit und Gegenwart. Geschichtliches und Kritisches, Heidelberg 1888, p. 176.

${ }^{14}$ H. Romundt, Recensão de P. Rée, Philosophie, in "Dresdner Anzeiger", 22 de novembo do 1903, p. 207.

${ }^{15}$ Cf. [P. Rée], Psychologische Beobachtungen. Aus dem Nachlass von..., Berlin 1875, depois in P. Rée, Gesammelte Werke 1875-1885, hrsg. von H. Treiber, Berlin-New York 2004, p. 59-125.

${ }^{16} \mathrm{Cf}$. A. Schopenhauer, Pararga und Paralipomena, II, in Werke in fünf Bänden, hrsg. von L. Lütkehaus, 6 Bde., Zürich 1988, Bd. V, capítulo 26, «Psychologische Bemerkungen», pp. 496-526.

${ }^{17}$ Cf. A. Schopenhauer, Parerga und Paralipomena, II, in Sämtliche Werke, hrsg. von A. Hübscher, 7 Bde., Wiesbaden 1948-1966, Bd. VI, p. 228. Schopenhauer cita de A. De Gobineau, Essai sur l'inegalité des races humaines [1853-1855], éd. par J. Gaulmier, Paris 1981-1983, II, p. 980.
} 
do gênero humano e também da variedade dos indivíduos". Tais pesquisas, escreve Schopenhauer, exigem uma "fina observação e inteligente compreensão, ou melhor, uma consideração a partir de um ponto de vista mais elevado, ou seja, de um ponto de vista de uma certa superioridade, que se pode encontrar nos escritos de espíritos excelentes como foram Teophrastus, Montaigne, La Rochefoucauld, La Bruyére, Helvetius, Chamfort, Addison, Schaftesbury, Shenstone, Lichtemberg e outros ainda" 18 .

Assim, a linha das pesquisas que guiou Rée nas suas Observações psicológicas e também a lista das suas leituras estão já delineados nos Parerga e Paralipomena de Schopenhauer. Mas no que diz respeito às características fundamentais do schopenhauerismo de Rée é preciso fazer algumas considerações.

As Observações psicológicas são um texto permeado por um pessimismo lúcido e desencantado: o homem é o animal malvado por excelência e seus atos estão sempre marcados pelo egoísmo, pelo conformismo, pela inveja e pela vaidade; o amor é um sentimento muito raro e o casamento dura só por uma questão de conveniência e por medo de escândalos; a religião é só um instrumento de controle social e os sacerdotes não passam de simuladores, alguns conscientemente, outros menos; a felicidade é uma ilusão destinada a desaparecer muito em breve e a pior coisa que pode acontecer a quem tem o passatempo de refletir sobre a vida é que tenha tempo para fazê-lo.

Schopenhauer fundou metafisicamente sua concepção pessimística da realidade, sua doutrina da dor do mundo: a vontade, que é o núcleo metafísico do todo, é uma força cega e irracional, um tender sem fim e sem descanso, que nunca poderá se apagar: por isso "a vida é um pêndulo que oscila [...] entre o sofrimento e o tédio" 19 .

Ao contrário de Schopenhauer, para afirmar sua visão pessimística, Rée não precisa nem de abstratas construções metafísicas, nem de postular alguma força cega e irracional como essência da realidade: para ele é suficiente a observação psicológica que, todos os dias, o põe de cara a cara com eloquentes exemplos de maldade e de miséria humana. Isso explica porque, ao invés de falar, como Schopenhauer, de Psychologische Bemerkungen, ou seja, de observações críticas

\footnotetext{
18 A. Schopenhauer, Parerga und Paralipomena, II, in Werke in fünf Bänden, cit., Bd. V, capítulo 1, «Über Philosophie und ihre Methode», p. 26.

${ }^{19}$ A. Schopenhauer, Die Welt als Wille und Vorstellung, I, in Werke in fünf Bänden, cit., Bd. 1, capítulo 57, p. 407.
} 
de psicologia empírica, Rée fala de Psychologische Beobachtungen, ou seja, da simples observação de uma realidade de fato.

Portanto, parafraseando o Nietzsche do Nascimento da tragédia, se poderia dizer que o de Rée é um pessimismo dos anos cinquenta sem nenhum vestígio da metafísica dos anos trinta ${ }^{20}$. Este aspecto caracteriza a posição de Rée também em relação aos outros discípulos de Schopenhauer, como Eduard von Hartmann, Julius Bahnsen e Philipp Mainländer, que fundaram suas doutrinas morais sobre uma transformação da metafísica de Schopenhauer e por isso, segundo a classificação da escola de Schopenhauer em sentido lato, são considerados como "os metafísicos". Isso não se dá no caso de Rée, que, nas Observações psicológicas não utiliza como ponto de partida a doutrina metafísica do Mundo, mas parte do filósofo moral dos Parerga e dos escritos de ética e, por isso, na escola de Schopenhauer, é classificado entre "os heréticos" 21.

Rée compartilha a concepção de Kant e de Schopenhauer segundo a qual o que determina a moralidade de um ato não são os fins e os objetivos que ele se propõe alcançar, mas os motivos que o determinam. Todavia, ao contrário de Schopenhauer, que vê no egoísmo, na maldade e na compaixão "as três motivações éticas do homem" 22 , segundo Rée, "na base de todos os atos há um mosaico de motivações, sem que saibamos quanto egoísmo, quanta vaidade, quanto orgulho, quanto medo, quanto amor pelo próximo o compõem. O filósofo não pode, como o químico, aplicar uma análise qualitativa e quantitativa" ${ }^{23}$. Ele, por isso, ao invés de postular a presença de poucas e bem determinadas motivações, tem que se limitar à observação empírica e a uma descrição que quase poderia se definir fenomenológica.

Além do mais, Rée torna sua a ideia de Schopenhauer que "a ausência de motivações egoísticas é o critério de um ato que tem valor moral" ${ }^{24}$, mas ao invés de basear este critério ético sobre o fundamento metafísico da compaixão - ou

\footnotetext{
${ }^{20}$ Cf. F. Nietzsche, Die Geburt der Tragödie, in Sämtliche Werke, cit., Bd. I, p. 21, "Versuch einer Selbstkritik", onde Nietzsche escreve que seu livro é "uma verdadeira profissão de fé romântica de 1830, sob a máscara do pessimismo de 1850 ".

${ }^{21}$ Cf. D. M. Fazio, La scuola di Schopenhauer. I contesti, in La scuola di Schopenhauer. Testi e contesti, cit., pp 148-164.

${ }^{22}$ A. Schopenhauer, Die Grundlage der Moral, in Werke in fünf Bänden, cit., Bd. 3, capítulo 16, p. 566.

23 P. Rée, Psychologische Beobachtungen, in Gesammelte Werke, cit., p. 65. Cf. F. Nietzsche, Menschliches Allzumenschliches I, in Sämtliche Werke, cit., aforismo 1, "Chemie der Begriffe und Empfindungen", pp. 23-24.

${ }^{24}$ A. Schopenhauer, Die Grundlage der Moral, in Werke in fünf Bänden, cit., Bd. 3, capítulo 15, p. 560.
} 
seja, sobre o fato que "um indivíduo reconhece si mesmo e o seu verdadeiro ser no outro", como escreve Schopenhauer ${ }^{25}$, e reconhece assim como própria a dor dele afirma explicitamente: "Que a bondade de um homem consiste na sua participação desinteressada no destino dos outros [...] todos o sabem por si mesmos e não precisam da filosofia moral para aprendê-10" 26 . O que cada um é depende da sua "natureza inata"27, ou seja, do que Schopenhauer chamava o caráter, e depende das circunstâncias da sua educação e da sua formação: a moral, consequentemente, não se pode ensinar, mas se podem melhorar os costumes, os comportamentos exteriores e para tal finalidade pode ser útil a filosofia moral.

E também não é possível ensinar os homens a serem felizes, porque, afirma Rée, "nossa felicidade depende mais do nosso temperamento do que da natureza do nosso coração". Por isso "os homens bons não são necessariamente felizes e os homens malvados não são necessariamente infelizes" ${ }^{28}$. Portanto, não é possível fundar uma eudemonologia, nem sequer dentro dos limites admitidos por Schopenhauer, ou seja, como a arte que ensina a ser o menos infelizes possível ${ }^{29}$.

A tese de Rée é que a felicidade completa e perfeita que os homens desejam é só uma ilusão. Nem é possível, para Rée, evitar a dor, que é a parte predominante da existência. O que, ao invés disso, é possível evitar é a brincadeira perversa das ilusões. E ele a descreve dessa maneira: um desejo que ainda não foi satisfeito gera a ilusão de uma possível felicidade futura. Ao contrário, um desejo satisfeito provoca inevitavelmente decepção e desilusão. E quanto maior é a ilusão da felicidade, tanto maior será a desilusão que inevitavelmente se produzirá.

Acontece sempre, escreve Rée, que "nossas esperanças nos tornam felizes enquanto não se realizam"30. E acrescenta: "Somos infelizes porque não possuímos os objetos que desejamos: mas isso é suportável. Somos infelizes porque a posse dos objetos de nossos desejos não nos torna felizes: e isso é insuportável” ${ }^{\text {31 }}$. Além disso, Rée observa que "A hipótese segundo a qual seríamos mais felizes em outras condições é sempre o pior componente da nossa condição atual”32. Mas

\footnotetext{
${ }^{25}$ A. Schopenhauer, Die Grundlage der Moral, in Werke in fünf Bänden, cit., Bd. 3, capítulo 22, p. 627.

${ }^{26}$ P. Rée, Psychologische Beobachtungen, in Gesammelte Werke, cit., p. 60.

${ }^{27}$ Ibidem.

${ }^{28}$ P. Rée, Psychologische Beobachtungen, in Gesammelte Werke, cit., p. 66.

${ }^{29}$ Cf. A. Schopenhauer, L'arte di essere felici, a cura di F. Volpi, Milano 1997.

${ }^{30}$ P. Rée, Psychologische Beobachtungen, in Gesammelte Werke, cit., p. 116.

${ }^{31}$ Ibidem.

32 Ibidem.
} 
infelizmente "Em relação às paixões e às ilusões que causam, a experiência dos outros não serve para nada e a experiência pessoal para quase nada"33: "a cabeça destrói as nossas ilusões, mas o coração as reconstrói sempre"34. Assim, parafraseando a célebre fórmula de Schopenhauer poderíamos dizer que, segundo Rée, a vida é um pêndulo que oscila entre a ilusão e a desilusão.

"Quem se convence que nada daquilo que pode ser possuído garante a felicidade tem que parar de desejar e de ser ativo. Essa inatividade (tédio), que deriva da náusea por qualquer atividade, é a verdadeira disposição do espírito ao suicídio" "35. O tema do suicídio é um clássico da filosofia schopenhaueriana e depois que Schopenhauer afirmou que "o suicídio não garante a salvação"36, entre os sequazes dele só Mainländer aceitará, com grande coerência, praticar pessoalmente o suicídio como caminho para o resgate do mundo ${ }^{37}$. Para Rée, ao contrário, a decisão do suicídio "deriva de um excesso de raciocínio"38, ou seja, de um excesso de desilusão, que é somente o resultado inevitável de um excesso de ilusão. Por isso, é preferível uma visão da vida e do mundo serenamente desencantada: essa ensina a valorizar seja as pequenas como as grandes felicidades da existência e também a suportar as dores, com total conscientização que nossa felicidade não depende da posse de bens exteriores, mas sim "do nosso temperamento" 39 e que "os bons e os maus estados de ânimo passam"

É esse o significado do apólogo do jardim antes do paraíso que Rée escreveu no último capítulo de suas Observações psicológicas: “O caso levou-me no jardim antes do paraíso. Enquanto vadiava extasiado, encontrei de repente uma porta. Eis aqui a entrada do paraíso, pensei. Abri a porta e atravessei o limiar. Ouvi a porta que se fechava atrás de mim. Olhei à volta com curiosidade e vi, com

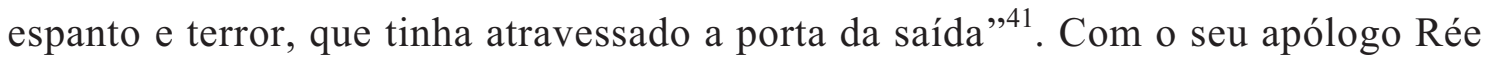
procura indicar aos homens um ideal de serenidade e de sabedoria que consiste em

\footnotetext{
33 P. Rée, Psychologische Beobachtungen, in Gesammelte Werke, cit., p. 115.

${ }^{34}$ P. Rée, Psychologische Beobachtungen, in Gesammelte Werke, cit., p. 114.

35 P. Rée, Psychologische Beobachtungen, in Gesammelte Werke, cit., p. 119.

36 A. Schopenhauer, Die Welt als Wille und Vorstellung, in Werke in fünf Banden, cit., Bd. I, capítulo 65, p. 473.

37 Cf. Ph. Mainländer, Die Philosophie der Erlösung, in Schriften, hrsg. von W. Müller-Seyfarth, 4 Bde., Hildesheim - Zurich - New York 1996, Bd. 1. Sobre esse autor da escola de Schopenhauer cf. F. Ciracì, Verso l'assoluto nulla. La Filosofia della redenzione di Philipp Mainländer, Lecce 2006.

38 P. Rée, Psychologische Beobachtungen, in Gesammelte Werke, cit., p. 119.

39 P. Rée, Psychologische Beobachtungen, in Gesammelte Werke, cit., p. 115.

40 P. Rée, Psychologische Beobachtungen, in Gesammelte Werke, cit., p. 120.

${ }^{41}$ P. Rée, Psychologische Beobachtungen, in Gesammelte Werke, cit., p. 114.
} 
não deixar que nem as ilusões nem as desilusões os perturbem, em aprender a desfrutar do pouco ou do muito que as circunstâncias concedem. E trata-se do antigo ideal de sabedoria que pertenceu aos Estoicos e aos Epicureus e que consiste na imperturbabilidade.

4. Em relação ao Paul Rée das obras sucessivas às Observações psicológicas escreveu-se que se tratava de um ex-schopenhaueriano que se convertera a uma forma de utilitarismo com tintas darwinianas ${ }^{42}$. E, efetivamente, naquelas obras o peso das influências de Schopenhauer torna-se sempre menor. Em A origem dos sentimentos morais, que Rée publicou em 1877, a herança antihistoricista de Schopenhauer entra em contradição com o evolucionismo de Darwin, que Rée utiliza para explicar a origem dos juízos morais ${ }^{43}$. Na Gênese da consciência, que Rée publicou em 1885, ele utiliza os resultados das contemporâneas pesquisas étnico-antropológicas, alcança um ponto de vista positivista e utilitarista e vai deixando sempre mais em segundo plano o pensamento de Schopenhauer ${ }^{44}$. No último texto que Rée publicou em sua vida, $A$ ilusão da liberdade da vontade. Suas causas e suas consequências, ele desenvolve um tema característico de Schopenhauer, assumindo uma posição coerentemente determinística. Sua posição, porém, aproxima-se mais à de Spinoza no "Voluntas non potest vocari causa libera, sed tantum necessária”, que à de Schopenhauer, dado que Rée não admite nem a liberdade transcendental, nem a imputabilidade moral ${ }^{45}$.

5. Mas será na obra póstuma Filosofia, editada em 1903, que Rée acertará as contas, explícita e definitivamente, com o schopenhauerismo de seus exórdios e assumirá uma posição em relação ao seu primeiro mestre. Escreve: "Schopenhauer é um observador sutil e rico de espírito, mas não é um pensador arguto. Falta-lhe o

\footnotetext{
${ }^{42}$ H. W. Ruckenbauer, Paul Rée oder die Betagtheit der evolutionären Ethik, in Moralität zwischen Evolution und Normen. Eine Ktitik biologistischer Ansätze in der Ethik, Würzburg 2002, p. 100 e 105.

${ }^{43}$ Cf. P. Rée, Der Ursprung der moralischen Empfindungen [1877], in Gesammelte Werke, cit., pp. 126211. Dessa obra existem também a tradução francesa (P. Rée, De l'origine des sentiments moraux, edition critique établie par P.-L. Assoun, traduit de l'Allemand par M.- F. Demet, Paris 1982) e a italiana (P. Rée, L'origine dei sentimenti morali, acura di D. Vignali, Genova 2005).

${ }^{44}$ Cf. P. Rée, Die Entstehung des Gewissens [1885], in Gesammelte Werke, cit., pp. 212-354.

${ }^{45}$ Cf. P. Rée, Die Illusion der Willensfreiheit. Ihre Ursachen und ihre Folgen, in Gesammelte Werke, cit., pp. 355-384. Cf. B. Spinoza, Ethica, I, 32.
} 
acume filosófico de um Berkeley, de um Hume, de um Mill. Seus erros são colossais, mas ele os considera como a solução do enigma do mundo"46.

Nessa última obra, Rée critica de maneira direta o núcleo central do pensamento de Schopenhauer, a metafísica da vontade, aquela metafísica da vontade que ele nunca aceitara. Que os homens e os animais queiram viver e procriar é, para Rée, um dado de fato incontestável, todavia, baseando-se sobre tal dado de fato Schopenhauer teria feito o que Rée chama "dois saltos de fantasia". O primeiro, pequeno, consiste em conceder a vontade inclusive ao mundo inorgânico. O segundo, maior e significativo, consiste em conceder a vontade também à coisa em-si: “A coisa em-si também quer viver e procriar”, mas assim Schopenhauer transforma a coisa em-si de Kant, que é a origem das representações, na coisa emsi como essência da realidade, operando aquela que Rée chama a "transfiguração da coisa em-si",47.

Em seus escritos Schopenhauer fez repetidamente profissão de ateísmo. Mas o ateu Rée, para o qual a verdadeira posição ateísta consiste na afirmação que os deuses não passam de personificações antropomórficas das forças da natureza, pergunta-se se Schopenhauer era um ateu coerente. Sua resposta está num aforismo de título malicioso: "A fé em Deus de Schopenhauer": "Schopenhauer troçou a fé em Deus: ao contrário, ele mesmo crê em Deus. Quais são as características distintivas de Deus. Deus, apesar de ser um ser ultramundano, manifesta-se no mundo: na sua existência, na organização conforme o fim dos animais, das plantas e dos homens, na voz da consciência. E que ensina Schopenhauer? A vontade, embora seja um ser ultramundano, manifesta-se no mundo: na sua existência, na organização conforme ao fim dos animais, das plantas e dos homens, na voz da consciência. Deus, enfim, pensa, a vontade não pensa. Mas que valor tem essa pequena diferença, de frente a tão grandes coincidências?"48.

Já nas Observações psicológicas Rée não compartilhava com Schopenhauer a ideia que a ética tivesse a necessidade de uma fundação metafísica. Em Filosofia ele apresenta suas teses de ética em contraposição com as de Schopenhauer, consentindo verificar com eficácia e imediação a distância que enfim o separa de

\footnotetext{
46 P. Rée, Philosophie, Nachgelassenes Werk, Berlin 1903, Gedanken über verschiedene Gegenstände der Philosophie», capítulo 4, "Die Philosophie Schopenhauers", aforismo 94, "Schopenhauer”, p. 290.

47 P. Rée, Philosophie, cit., "Gedanken über verschiedene Gegenstände der Philosophie", capítulo 4, "Die Philosophie Schopenhauers", aforismos 98, "Worte", e 99, “Transfigurationen”, pp. 293-297.

48 P. Rée, Philosophie, cit., "Gedanken über verschiedene Gegenstände der Philosophie"capítulo 4, "Die Philosophie Schopenhauers", aforismo 106, "Schopenhauers Gottesglaube”, pp. 301-302.
} 
seu antigo mestre: "O problema moral da louvabilidade da compaixão consiste em dois problemas: 1. A compaixão é uma manifestação do instinto do amor pelo próximo, que, como todos os instintos, pode ser explicado como um fenômeno natural. Dado que a explicação científica do instinto de amor pelo próximo ainda não foi encontrada, é preciso adiar a explicação da compaixão. Explicação de Schopenhauer. Na compaixão desaparece a individuação e manifesta-se a unidade entre quem é objeto da compaixão e quem compadece. 2. O caráter de louvabilidade da compaixão, criado a vantagem dos homens, produto da civilização, é nos povos civilizados um hábito. Explicação de Schopenhauer. A vontade não quer a individuação. Isso revela-se no louvor que os homens tributam à compaixão" 49 .

Essas são as conclusões às que Rée chega desenvolvendo e radicalizando com coerência as originárias premissas antimetafísicas do seu pensamento. E por isso ele pode concluir a sua confrontação crítica com a filosofia de Schopenhauer com esse juízo, que parece uma definitiva aniquilação: "A filosofia de Schopenhauer não é uma análise do mundo, mas uma fantasia sobre o mundo"

6. Mas a herança de Schopenhauer continua a estar presente na orientação prática que Rée deu aos últimos anos da sua vida, ou seja, na sua atividade de médico e filantropo. Depois de 1885, com o fim de suas esperanças de obter uma cátedra acadêmica em filosofia, Rée matriculou-se na faculdade de medicina e licenciou-se em Munique em 1890. Obtido o diploma, regressou à propriedade de família, em Stibbe, onde por dez anos exerceu a profissão de médico e, coerentemente com suas convicções filosóficas, consagrou todo seu tempo e todas suas energias a ajudar, com suas competências em medicina e com seus recursos financeiros, os pobres e os doentes que moravam ali. Assistia e os curava gratuitamente, os sustentava e, quando era necessária a hospitalização deles em alguma clínica universitária, pagava todos os gastos. Por isso os camponeses de Stibbe o consideravam uma espécie de santo $^{51}$. Em 1900 a propriedade de Stibbe foi vendida e Rée transferiu-se para um povoado dos Alpes helvéticos, onde

49 P. Rée, Philosophie, cit., "Gedanken über verschiedene Gegenstände der Philosophie" capítulo 4, "Die Philosophie Schopenhauers", aforismo 129, "Schopenhauers Moralphilosophie", pp. 320-321.

${ }^{50}$ P. Rée, Philosophie, cit., "Gedanken über verschiedene Gegenstände der Philosophie" capítulo 4, "Die Philosophie Schopenhauers", aforismo 140, "Sehen und Folgern", p. 326.

${ }^{51}$ Cf. K. Kolle, Notizien über Paul Rée, in "Zeitschrift für Menschenkunde", 1927, pp. 168-174 e L. Lütkehaus, Ein heiliger Immoralist. Paul Rée, Marburg 2001. 
prosseguiu a sua atividade de filantropo, pondo suas competências médicas a serviço da população daqueles montes. No dia 28 de Outubro de 1901, durante um passeio solitário pelos montes, morreu, precipitando num penhasco. Foi uma desgraça ou suicidou-se? Na cópia da fotografia da "trindade" que lhe pertencia, que foi reencontrada por Ludger Lütkehaus, Rée tinha cancelado o próprio rosto. Quando? Por quê? 